\title{
The use of wastes as alternative fuels in cement production
}

\author{
J. Karagiannis ${ }^{1}$, Ch. Ftikos ${ }^{2}$ \& P. Nikolopoulos ${ }^{3}$ \\ ${ }^{1}$ Hellenic Cement Research Ctr., Athens, Greece \\ ${ }^{2}$ Faculty of Chemical Engineering, \\ National Technical University of Athens, Greece \\ ${ }^{3}$ Department of Chemical Engineering, University of Patras, Greece
}

\begin{abstract}
The high burning temperature, the long retention time inside the kiln, the oxidizing atmosphere, the ash absorption in the clinker and the chemical conditions render the cement kilns ideal installations where wastes can be burned safely. Consequently, some of the wastes may be potential candidates to be used as alternative fuels in cement production that boasts a lot of environmental benefits. These wastes include a variety of materials like used tires, animal meal, refused derived fuels (RDF), solvents, used oils, biomass etc. During the clinker production process, the organic part of the wastes is totally destroyed whereas the inorganic compounds and heavy metals are incorporated in the interstitial phase or substitute calcium or silicon in the silicate phases of the clinker. However, due to their origin these wastes introduce into the cement making process several trace elements that may affect the process itself as well as the properties of clinker.

This work investigates the effects of the use of biomass (cotton stalks) and $\mathrm{RDF}$ on the properties of Portland cement clinker. In this respect, ash of these two waste materials was introduced in the raw mix in diverse proportions. The clinkerization characteristics and the microstructure of the lab prepared raw mixes and of the reference mixture were investigated by Differential Thermal Analysis-Thermogravimetry (DTA/TG), Optical Microscopy (OM) and X-Ray Diffraction (XRD). The derived results suggest that both waste materials, RDF and cotton stalks can be used as an alternative to replace fossil fuels, such as coal, for the production of Portland cement clinker.
\end{abstract}

Keywords: wastes, alternative fuels, portland cement clinker, trace elements. 


\section{Introduction}

The European cement industry produces annually about 170 million tons of cement. This is produced under rigorous quality specifications imposed by the European and national legislation and relevant internal procedures. Strict regulations apply in cement plants operation which is based upon permission of the pertinent authorities. The cement industry is able to use wastes as alternative fuels in order not only to boost its competitiveness, but also to contribute in the social problem of waste management with an environmental - oriented solution. Today the use of alternative fuels in European countries reaches up to 4 million tons/year, substituting around 2,5 million tons of coal per year [1].

The use of wastes as alternative fuels in cement production boasts a lot of environmental benefits shown below:

a. Reduces the use of non - renewable sources like coal as well as the environmental impact by its mining.

b. Contributes towards the reduction of gas emissions responsible for the greenhouse effect by replacing fossil fuels by materials that in another case should have been disposed or burned with the negative impact on the environment.

c. Maximizes energy recovery from wastes. All the energy is used directly within the rotary kiln for clinker production. Also maximizes the recovery of the non-combustible part of the waste (ash) and eliminates any need for its disposal as the remaining inorganic compounds are incorporated in the clinker.

During the clinker production process, the organic part is totally destroyed whereas the inorganic compounds and heavy metals are incorporated in the interstitial phase or substitute calcium or silicon in the silicate phases of the clinker [2-4].

The high burning temperature, the long retention time inside the kiln, the oxidizing atmosphere, the ash absorption in the clinker and the chemical conditions render the cement kilns ideal installations where wastes can be burned safely $[5,6]$.

Alternative fuels include a variety of materials like used tires, animal meal, refused derived fuels (RDF), solvents, used oils, biomass etc.

The present work, being part of an extensive research program, aims to investigate the properties of clinker burned in laboratory furnace in the presence of RDF and biomass (cotton stalks in this case) used as coal replacements. Their materials present a significant calorific value compared to that of coal. Also large amounts of such materials are available domestically to cover the need of cement plants. The mixture design was based upon a $100 \%$ replacement of coal by wastes. Therefore, the respective portion of ash of RDF and cotton stalks was introduced in the raw mix. In addition, mixtures containing half and double the amount of the waste input were also examined in comparison. As reference sample (M1C) the same raw mix was used containing conventional coal ash. The clinkering behavior of the initial mixtures was assessed by differential thermal 
analysis and thermogravimetric analysis (DTA/TG). The resulting clinkers were investigated by X-Ray Diffractometry (XRD) and Optical Microscopy (OM).

\section{Experimental procedure}

\subsection{Materials}

The raw mix used in this work was provided by the Cement Company AGET Heracles and corresponds to a typical industrial grey raw mix design. Its chemical analysis performed by means of X-Ray Fluoresence (XRF) is illustrated in Table 1. The mineral investigation of the raw mix carried out by means ofXRD technique revealed mainly the presence of calcite $\left(\mathrm{CaCO}_{3}\right)$ and quartz $\left(\mathrm{a}-\mathrm{SiO}_{2}\right)$. As secondary phases dolomite $\left(\mathrm{CaMg}\left(\mathrm{CO}_{3}\right)_{2}\right)$, albite $\left(\mathrm{NaAlSiO}_{8}\right)$, and illite $\left(\mathrm{KAl}_{2}\left(\mathrm{Si}_{3} \mathrm{Al}\right) \mathrm{O}_{10}(\mathrm{OH})_{2}\right)$ were identified. The $90 \mu \mathrm{m}$ residue was $13.3 \%$.

Table 1: $\quad$ Chemical analysis of the raw mix.

\begin{tabular}{|c|c|c|c|c|c|}
\hline Oxides & $\mathbf{( \% )}$ & $\begin{array}{c}\text { Trace } \\
\text { elements }\end{array}$ & (ppm) & Trace elements & (ppm) \\
\hline $\mathrm{SiO}_{2}$ & 13.29 & $\mathrm{Tl}$ & 15 & $\mathrm{Ni}$ & 40 \\
\hline $\mathrm{Al}_{2} \mathrm{O}_{3}$ & 3.55 & $\mathrm{~Pb}$ & 22 & $\mathrm{Hg}$ & 0.3 \\
\hline $\mathrm{Fe}_{2} \mathrm{O}_{3}$ & 2.28 & $\mathrm{As}$ & 35 & $\mathrm{Sb}$ & 1,4 \\
\hline $\mathrm{CaO}$ & 42.85 & $\mathrm{Cd}$ & $<1$ & $\mathrm{Mn}$ & 210 \\
\hline $\mathrm{MgO}$ & 1.37 & $\mathrm{Co}$ & 7 & $\mathrm{~V}$ & 42 \\
\hline $\mathrm{K}_{2} \mathrm{O}$ & 0.38 & $\mathrm{Cu}$ & 39 & & \\
\hline $\mathrm{Na}_{2} \mathrm{O}$ & 0.32 & $\mathrm{Cr}$ & 65 & & \\
\hline $\mathrm{SO} 3$ & 0.01 & $\mathrm{Zn}$ & 77 & & \\
\hline
\end{tabular}

Table 2: $\quad$ Composition of waste ash.

\begin{tabular}{|c|c|c|c|c|c|}
\hline Oxides & RDF (\%) & $\begin{array}{c}\text { Cotton stalks } \\
(\mathbf{\%})\end{array}$ & Oxides & $\begin{array}{c}\text { RDF } \\
\mathbf{( \% )}\end{array}$ & $\begin{array}{c}\text { Cotton stalks } \\
(\mathbf{\%})\end{array}$ \\
\hline $\mathrm{SiO}_{2}$ & 24,92 & 0,64 & $\mathrm{ZnO}$ & 0,188 & 0,023 \\
\hline $\mathrm{Al}_{2} \mathrm{O}_{3}$ & 12,72 & 2,60 & $\mathrm{PbO}$ & 0,032 & 0,010 \\
\hline $\mathrm{Fe}_{2} \mathrm{O}_{3}$ & 3,32 & 0,80 & $\mathrm{MnO}$ & 0,076 & 0,061 \\
\hline $\mathrm{CaO}$ & 43,68 & 27,23 & $\mathrm{CuO}$ & 0,056 & 0,025 \\
\hline $\mathrm{MgO}$ & 4,40 & 11,01 & $\mathrm{NiO}$ & 0,050 & 0,007 \\
\hline $\mathrm{SO}_{3}$ & 2,07 & 7,19 & $\mathrm{TiO}$ & 1,940 & 0,200 \\
\hline $\mathrm{K}_{2} \mathrm{O}$ & 1,14 & 29,88 & $\mathrm{SnO}$ & 0,048 & traces \\
\hline $\mathrm{Na}_{2} \mathrm{O}$ & 3,12 & 5,32 & $\mathrm{~V}_{2} \mathrm{O}_{5}$ & traces & traces \\
\hline $\mathrm{Cl}$ & 0,80 & 0,32 & $\mathrm{CoO}$ & 0,010 & 0,028 \\
\hline $\mathrm{Cr}_{2} \mathrm{O}_{3}$ & 0,15 & 0,04 & $\mathrm{P}_{2} \mathrm{O}_{5}$ & 5,860 & 4,760 \\
\hline
\end{tabular}


The RDF was provided by a domestic waste treatment installation. This is a mixture of fabric, plastic and paper which is about $88 \%$ combustible. The cotton stalks were provided by local agricultural areas and are about $95 \%$ combustible. The chemical analysis of the ash for both waste materials used is presented in Table 2. Lower H V and the ash content for these materials is shown in Table 3.

Table 3: $\quad$ LHV and ash content of fuels.

\begin{tabular}{|l|c|c|}
\hline \multicolumn{1}{|c|}{ Fuel } & LHV (J/g) & \% Ash content \\
\hline Coal & 30210 & 9.1 \\
\hline RDF & 19672 & 11.8 \\
\hline Cotton stalks & 20260 & 5.24 \\
\hline
\end{tabular}

\subsection{Sample preparation}

Based upon industrial data $7.32 \mathrm{~kg}$ of coal are needed $/ 100 \mathrm{~kg}$ of raw mix. Taking into account the LHV of the coal this means $2211.4 \mathrm{~kJ} / \mathrm{kg}$ of raw mix and the respective coal ash residue, namely $0.726 \mathrm{~kg}$, is incorporated into the clinker during burning. Relatively with these data and taking into account the LHV's and the ash contents referred to Table 3, three basic mixtures were prepared; the reference mixture with coal (M1C) and the mixtures M2R and M2B with a $100 \%$ substitution of coal by RDF and cotton stalks respectively. Furthermore, for each one of the wastes used two more mixtures were prepared that contained half (M1R, M1B) and double (M3R, M3B) of the ash percentage determined for the mixture M2R and M2B). Table 4 illustrates the synthesis and the identification of the mixtures prepared.

Table 4: $\quad$ Synthesis and identification of the mixtures prepare.

\begin{tabular}{|l|c|c|c|c|c|c|c|}
\hline $\begin{array}{l}\text { Mixture } \\
\text { Name }\end{array}$ & $\begin{array}{c}\text { M1 } \\
\text { C }\end{array}$ & M1R & M2R & M3R & M1B & M2B & M3B \\
\hline $\begin{array}{l}\text { Raw mix } \\
\text { weight (g) }\end{array}$ & 10 & 10 & 10 & 10 & 10 & 10 & 10 \\
\hline Coal Ash (g) & $\begin{array}{c}0,07 \\
26\end{array}$ & & & & & & \\
\hline RDF ash (g) & & 0,1054 & 0,2108 & 0,4216 & & & \\
\hline $\begin{array}{l}\text { Cotton stalks } \\
\text { ash (g) }\end{array}$ & & & & & 0,0283 & 0,0566 & 0,1132 \\
\hline $\begin{array}{l}\text { Ash in the } \\
\text { raw mix (\%) }\end{array}$ & 0,72 & 1,04 & 2,06 & 4,05 & 0,28 & 0,56 & 1,12 \\
\hline
\end{tabular}

The mixture preparation procedure included weighing of the portion of the materials (raw mix and ash) and dry mixing. Pellets were prepared from the resulting mixtures by addition of water. The pellets were dried at $100^{\circ} \mathrm{C}$ and then burned in a programmable furnace, with a rate of $10^{\circ} \mathrm{C} / \mathrm{min}$, at this temperature for 30 minutes, following air cooling at room temperature. 


\section{Results and discussion}

\subsection{Thermal analysis of mixtures}

Thermal analysis was performed to simulate the conditions existing in the rotary kiln during clinkering [7-9]. All mixtures were subjected to thermal and thermo gravimetric (DTA/DTG) analyses in air atmosphere. The temperature profile used for heating was identical to that followed for the clinkerization of the pellets in the lab furnace.

The DTA/TG diagrams are presented in Figure 1, (a) for the mixtures M1R, M2R, M3R and (b) for M1B, M2B, M3B in comparison with the reference mixture M1C. All the main reaction peaks observed and the corresponding temperatures are summarized in Table 5 .

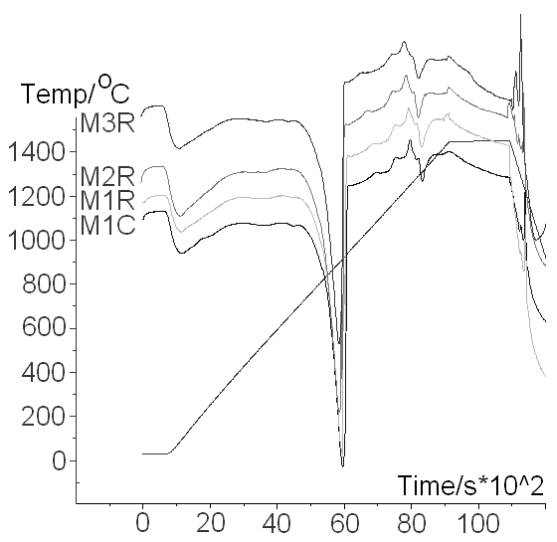

(a)

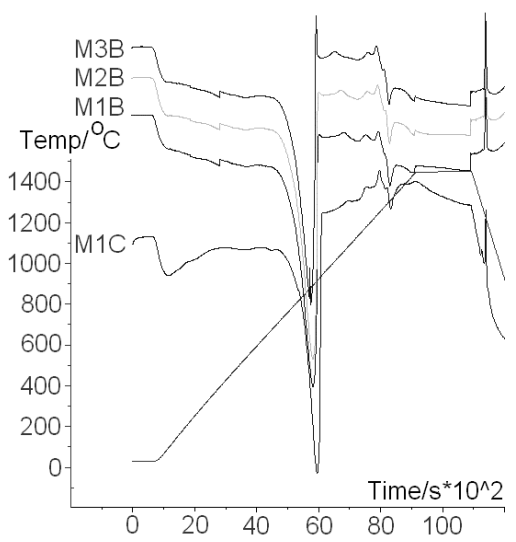

(b)

Figure 1: DTA and DTG curves of the reference mixture M1C in comparison to the mixtures containing (a) RDF and (b) cotton stalks ash.

Table 5: Temperatures of the main reaction peaks occurring during the heating of the mixtures.

\begin{tabular}{|c|c|c|c|}
\hline Mixture & \multicolumn{3}{|c|}{ Peak point $\left.\mathbf{(}^{\mathbf{}} \mathbf{C}\right)$} \\
\hline $\begin{array}{c}\text { M1C } \\
\text { (Reference) }\end{array}$ & 914,7 & 1249,9 & $\begin{array}{c}\text { Liquid phase } \\
\text { formation }\end{array}$ \\
\hline M1R & 912,7 & 1243,4 & 1310,1 \\
\hline M2R & 908,0 & 1238,7 & 1308,6 \\
\hline M3R & 907,2 & 1228,5 & 1301,3 \\
\hline M1B & 894.6 & 1248.9 & 1308.9 \\
\hline M2B & 894.5 & 1243.0 & 1307.9 \\
\hline M3B & 880.8 & 1237.3 & 1305.4 \\
\hline
\end{tabular}


The DTA-TG curves clearly show the stage of drying caused by loss of raw mix moisture at about $100^{\circ} \mathrm{C}$ (broad endothermic peak). At $915^{\circ} \mathrm{C}$ a major endothermic peak appears due to the decomposition of calcite, involving loss of carbon dioxide. Right after a very small exothermic peak occurs, connected to the initiation of belite formation. The formation of aluminate and calcium aluminate ferrite is indicated by small endothermic heat effects between 1100 and $1220^{\circ} \mathrm{C}$.

The formation of belite is represented by a well formed exothermic peak at $1250^{\circ} \mathrm{C}$ followed by the endothermic effect of liquid phase formation at $1310^{\circ} \mathrm{C}$. The formation of alite occurs above $1350^{\circ} \mathrm{C}$ and does not show a clear exothermic peak. During the subsequent cooling of the sample a sharp exothermic peak appears at $1200^{\circ} \mathrm{C}$ attributed to the crystallization of the molten phase. As revealed by DTA results showed in Table 5, being sample, but temperature shifts of the reaction peaks are observed during clinkerization compared to the reference mixture.

Both mixtures containing RDF and cotton stalks ash present lower decarbonation temperatures with increasing ash content. The belite formation and liquid phase formation temperatures are also shifted in the same way

\subsection{X-Ray Diffraction (XRD) study}

XRD analyses were carried out by a Rigaku D/MAX-IIVC Geigerflex. All specimens were ground to fine powders. XRD scanning was performed within the range $5^{\circ}-70^{\circ}$ in steps of $0.02^{\circ} 2 \theta$ using $\mathrm{CuKa}$ radiation.

The study of the XRD patterns shown in Figure 2, reveals that all the specimens prepared contain all the major clinker phases, namely, alite $\left(\mathrm{C}_{3} \mathrm{~S}\right)$, belite $\left(\mathrm{C}_{2} \mathrm{~S}\right)$, ferrite $\left(\mathrm{C}_{4} \mathrm{AF}\right)$ and aluminate $\left(\mathrm{C}_{3} \mathrm{~A}\right)$. Table 6 summarises the main peak $2 \theta$ position of the two main calcium silicate compounds $\left(\mathrm{C}_{2} \mathrm{~S}\right.$ and $\left.\mathrm{C}_{3} \mathrm{~S}\right)$. The comparison of the corresponding peaks between the clinkers containing waste ash and the reference one (M1C) does not reveal any significant difference that would suggest any structural modification caused by the trace metal effect contained in the waste ash add.

Table 6: $2 \theta$ comparison of the main calcium silicate peaks.

\begin{tabular}{|c|c|c|c|}
\hline Mixture & \multicolumn{3}{|c|}{$\left(\mathbf{2 \theta}^{\mathbf{}}\right)$} \\
\hline M1C (Reference) & 32.200 & 32.619 & 34.362 \\
\hline M1R & 32.201 & 32.619 & 34.374 \\
\hline M2R & 32.240 & 32.600 & 34.361 \\
\hline M3R & 32.200 & 32.600 & 34.361 \\
\hline M1B & 32.220 & 32.638 & 34.363 \\
\hline M2B & 32.182 & 32.600 & 34.360 \\
\hline M3B & 32.201 & 32.619 & 34.379 \\
\hline
\end{tabular}




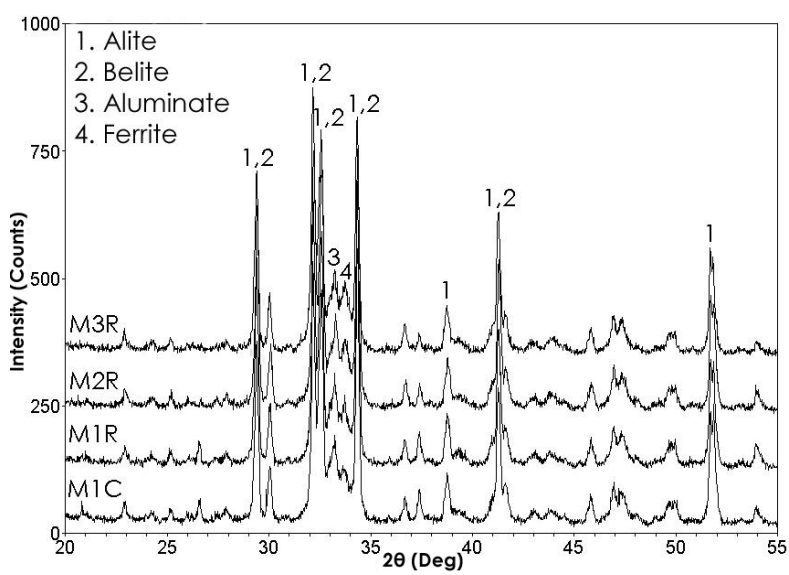

(a)

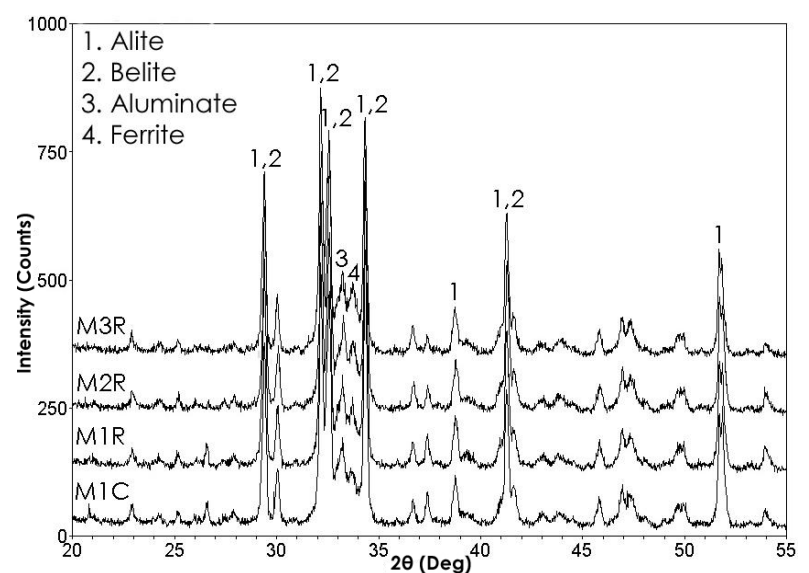

(b)

Figure 2: $\quad \mathrm{XRD}$ patterns of the reference mixture M1C in comparison to the mixtures containing (a) RDF (M1R, M2R, M3R), and (b) cotton stalks (M1B, M2B, M3B) ash.

\subsection{Optical Microscopy (OM) study}

Clinkers prepared were mounted in epoxy resin, cut through a cross section and polished. The polished sections were then etched with $40^{\circ} \mathrm{C}$ de-ionized water, $1 \%$ nital and $1 \%$ aqueous $\mathrm{NH}_{4} \mathrm{CL}$. Microscopical evaluation was performed in reflected light. Some representative photos of the clinkers examined by means of the optical microscopy are presented in Figure 3.

High porosity was observed in the samples probably due to the preparation method (pelletizing) and clinkering conditions. The numerous belite clusters also observed could be attributed to the same reason [10]. 
The examination of the reference clinker M1C showed idiomorphic, angular alite crystals with a size between $20-25 \mu \mathrm{m}$. The crystals were usually fused. The crystals of belite were in general round with multiple sets of lamellae. Their size was between 25-30 $\mu \mathrm{m}$. The interstitial phase (aluminate and ferrite) was generally finely crystallized due to the rapid cooling process (Fig. 3a and 3b).

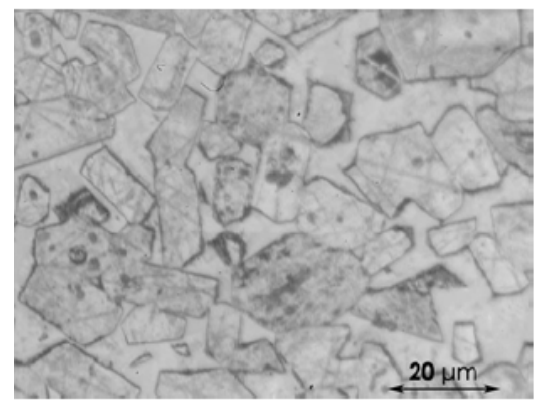

(a)

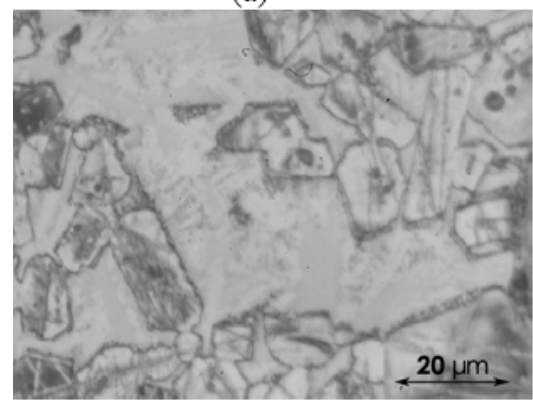

(c)

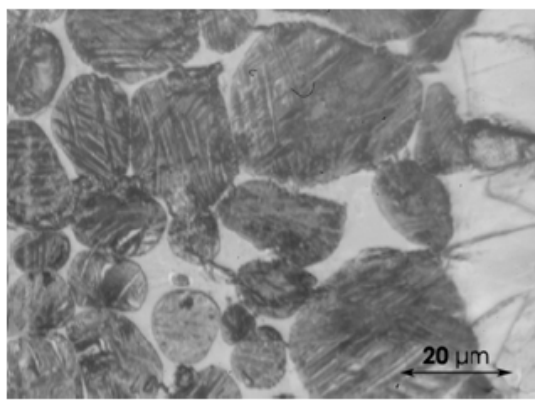

(b)

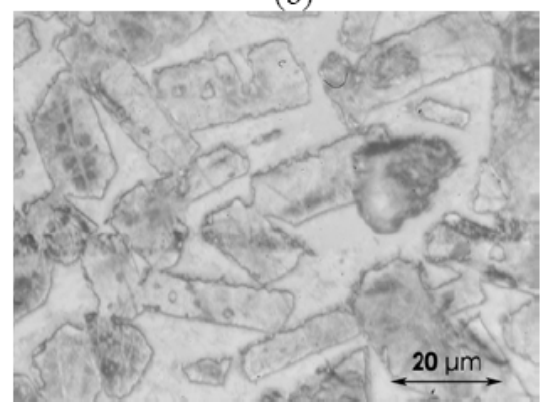

(d)

Figure 3: $\quad$ OM photos, (a) clinker M1C showing fused alite crystals of small size, (b) clinker M1C showing round belite crystals with multiple sets of lamellae on their surface, (c) clinker M1R with coarsely crystallized interstitial phase and some alkali aluminate, (d) clinker M1B showing deteriorated alite crystals of small size.

In the case of the clinker with RDF ash addition the alite crystals appeared angular in general, but in some cases belite fringing around their circumference attributed to some decomposition. The crystal size is about $25 \mu \mathrm{m}$ and partially fused. The belite crystals retained their round shape, size and multilamellae character. The aluminate compounds of the interstitial phase observed in some case affected by alkali incorporation in its lattice thus crystallized in orthorhombic symmetry (Fig. 3c).

The clinkers containing ash from cotton stalks have in general similar microstructure to those containing RDF ash. Some of the alite crystals appeared to be deteriorated (Fig.3d). Finally, some alkali aluminates were also observed. 


\section{Conclusions}

Summarising the conclusions derived from the above results, concerned with the effect of the two waste materials used, RDF and cotton stalks, on the clinker formation it is concluded that the clinkers produced contain all the main phases alite, belite, aluminate and ferrite. The crystal structure of these phases are quite similar to those of the reference clinker. Furthermore, the use of these waste materials have a positive effect on the clinkering by means of promoting the formation of the major clinker phases and shifting their reactions to lower temperatures in comparison to the reference clinker M1C.

These conclusions suggest that the two waste materials used, RDF and cotton stalks, are very potential candidates to replace fossil fuels like coal for the production of Portland cement clinker. However, further investigations are needed by means of the hydration and strength development of the cement produced with the materials concerned.

\section{Acknowledgements}

This project is co-funded by the European Social Fund (75\%) and National Resources (25\%) - EPEAEK II.

\section{References}

[1] Hellenic Cement Industries Association (HCIA), Information available on line at the site $h t t p: / / w w w . h c i a . g r$

[2] M. Murat, F. Sorrentino, "Effect of large additions of $\mathrm{Cd}, \mathrm{Pb}, \mathrm{Cr}, \mathrm{Zn}$ to cement raw meal on the composition and the properties of the clinker and the cement", Cement \& Concrete Research 26 (3), pp. 377-385, 1996.

[3] G. Kakali, V. Kasselouri, G. Parissakis, "Investigation of the effect of Mo, $\mathrm{Nb}$, Wand $\mathrm{Zr}$ oxides on the formation of portland cement clinker", Cement \& Concrete Research, 20 (1) pp. 131-138, 1990.

[4] G. Kakali, S. Tsivilis, A. Tsialtas, "Hydration of ordinary Portland cements made from raw mix containing transition element oxides", Cement \& Concrete Research 28 (3) pp. 335-340, 1998.

[5] M.A. Trezzaa, A.N. Scianb, "Waste fuels: their effect on Portland cement clinker" Cement and Concrete Research, Article in press 2004.

[6] P.G. Ract, D.C.R. Espinosa, J.A.S. Tenorio, "Determination of $\mathrm{Cu}$ and $\mathrm{Ni}$ incorporation ratios in Portland cement clinker", Waste Management 23, pp. 281-285 2003.

[7] G. Kakali, G. Parissakis, D. Bouras, "A Study on the Burnability and the Phase Formation of PC Clinker Containing $\mathrm{Cu}$ Oxide", Cement and Concrete Research, Vol. 26, No. 10, pp. 1473-1478, 1996.

[8] Handa, S.K., Raina, S.J., "Cement Raw Mix Characterization by Differential Thermal Analysis", Thermochimica Acta, 93: pp. 609-612, 1985. 
[9] V.S. Ramachandran, Ralph M. Paroli, James J. Beaudoin, Ana H. Delgado, "Handbook of thermal analysis of Construction Materials", pp. 77-89, 2002.

[10] Hills, Linda M., Tang Fulvio J., "The Effect of Alternate Raw Materials on Clinker Microstructure \& Cement performance: Two Case Studies".

[11] D. Stephan, D. Knöfel, B. Eber, R. Härdtl, "Influence of Cr, Ni, and Zn on the properties of pure clinker phases; Part I: $\mathrm{C}_{3} \mathrm{~S}$ ", Cement and Concrete Research 29 pp. 545-552, 1999.

[12] D. Stephan, D. Knöfel, B. Eber, R. Härdtl, "Influence of Cr, Ni, and Zn on the properties of pure clinker phases Part II. $\mathrm{C}_{3} \mathrm{~A}$ and $\mathrm{C}_{4} \mathrm{AF}$ ", Cement and Concrete Research 29, pp. 651-657, 1999.

[13] D. Stephan, R. Mallmann, D. Knöfel, R. Härdtl, "Influence on burning process and formation of phase, Cement and Concrete Research 29, pp. 1949-1957, 1999. 